\title{
Initial Analysis of Fire Weather Characteristics between South-East Australia and South-West of Western Australia
}

\author{
$\underline{\text { X. G. Lin }}{ }^{\text {a }}$, A. L. Sullivan ${ }^{\text {b }}$, A. G. Stephenson ${ }^{\mathrm{c}}$ and S. Dunstall ${ }^{\mathrm{c}}$ \\ ${ }^{a}$ CSIRO Computational Informatics, GPO Box 664, Canberra, ACT 2601, Australia \\ ${ }^{\mathrm{b}}$ CSIRO Ecosystem Sciences, GPO Box 1700, Canberra, ACT 2601, Australia \\ ${ }^{\mathrm{c}}$ CSIRO Computational Informatics, Private Bag 33, Clayton South MDC, VIC 3168, Australia \\ Email: Xunguo.Lin@csiro.au
}

\begin{abstract}
Australia is a continent in which bushfires are an endemic part of the landscape. A bushfire can occur anywhere at some time of the year, restricted by the presence of flammable fuel, conducive weather conditions and an ignition source.

Due to its size, Australia spans a wide range of geological and climatological zones, resulting in a large number of unique landscapes, from arid desert to rainforest to alpine, the genesis of a number of significant differences in fire weather between the east coast and west coast of the continent.

The potential for disastrous fire is dictated by three factors that influence fire behaviour: (a) the type of vegetation (fuel) in which the fire is burning; (b) the weather; and (c) the topography in which the fire burns.

This paper centers on (b) the weather, particularly the fire danger weathers measured by the McArthur Forest Fire Danger Index (FFDI). It concentrates on the comparison of fire danger weather conditions of south-east of Australia and south-west of Western Australia.

Weather datasets since 1990 from almost all Automatic Weather Stations in Australia were acquired and 28 were selected and analysed. Furthermore, six sites were particularly chosen, one for each state/territory, for this comparison study.

A number of fire danger severity measures were developed including the number of Extreme FFDI days per fire season and the longest number of consecutive Extreme FFDI days. The paper has a number of findings including the similarities of fire weather conditions of the two regions and their differences. This initial analysis motivates us to engage further research on other important fire risk factors such as vegetation, distribution of infrastructure, properties and population at risk, and possible correlation between the past fire ignitions including disastrous fire events and FFDI.
\end{abstract}

Keywords: Fire weather conditions, forest fire danger index, fire ecology 


\section{INTRODUCTION}

Australia is a continent in which bushfires are an endemic part of the landscape. A bushfire can occur almost anywhere at some time of the year, restricted by the presence of flammable fuel, conducive weather conditions and an ignition source. Given the right conditions, any vegetative matter will become flammable and carry a fire. The occurrence of the right conditions is generally driven by the weather and defines the bushfire season (Luke and McArthur, 1978). This is primarily controlled by the nature of the climate (rainfall patterns) and solar radiation (drying patterns) (Sullivan et al., 2012).

The potential for disastrous fire is dictated by the factors that influence fire behaviour as well the values put at risk by the fire. The factors that influence fire behaviour are:

- the type of vegetation (fuel) in which the fire is burning,

- the weather, and

- the topography in which the fire burns.

These factors form what is called the fire behaviour triangle (Countryman, 1966). The interaction of these three factors plus the fire itself will determine the speed at which the fire spreads, its intensity and its potential for impact (Cheney et al., 1993). In southern Australia, the potential for disastrous fires coincides with the greater topographic relief and denser vegetation (tall wet and dry forests) of the south-west and south-east as well as the more extreme fire weather (those weather components that drive fire behaviour: wind, humidity, rain and air temperature).

A number of studies (e.g., Fox-Hughes (2008)) have been conducted that consider the national impact of subglobal climate phenomena such as El Niǹo-Southern Oscillation (ENSO) and more broader aspects such as climate change on the current and future fire danger, which provide some insights into the relative risks for each State. More common, however, are studies that look at the fire weather climatology for a particular state. While these too can provide some insight into the comparative differences between States, they often do not use compatible methodologies that enable cross-study comparisons.

This paper attempts to identify the comparative differences in fire risk between Western Australia (WA) and the eastern states (Victoria, New South Wales (NSW), South Australia (SA) and Tasmania). While differences in vegetation type do exist across the continent, these are predominantly of a species composition nature and not in the morphology or structure which influences fire behaviour (Sullivan et al., 2012). Forests are dominated by dry sclerophyll forests with smaller pockets of wet sclerophyll forest in various combinations of which eucalypts are the most common genera. Thus, the focus of the investigation is on the differences in topography and fire weather climatology (which itself is affected by the topography). As topography is static the bulk of this paper focuses upon the differences in fire weather climatology between the two ends of the continent.

\section{COMParison OF EAST/WeSt Fire RISK}

\subsection{Topography, climate and fuels}

While much of the Australian landscape (Figure 1) is considered to be of low fertility in comparison with other continents, the soils in WA are particularly infertile and frequently laterised due to the extreme age of the landscape. Much of the state is dry arid desert supporting little productive grassland with hummock grasslands (spinifex) and shrublands the dominant vegetation types. It is only the south-west corner of the state that receives sufficient rainfall to sustain the tall dry and wet sclerophyll forests. In comparison much of the east coast supports productive farmland consisting of improved pasture as well as extensive dry sclerophyll forests, primarily on the steeper slopes that were not cleared for farming.

Due to its size, Australia spans a wide range of geological and climatological zones, resulting in a large number of unique landscapes including deserts, rainforests and alpine areas, the genesis of a number of significant differences between the east and west coasts of the continent. Despite the presence of a number of mountain ranges, it is the flattest continent with the oldest and least fertile soils. Eastern Australia is marked by the Great Dividing Range, running parallel to the coast through Queensland, NSW and much of Victoria, generally ranging in elevation from 300-1600 m with the peak at $2228 \mathrm{~m}$ (Mt Kosciuszko). It is approximately $3500 \mathrm{~km}$ long and $190 \mathrm{~km}$ wide at its widest. Western Australia, on the other hand, is extremely eroded with no peak above $1245 \mathrm{~m}$. Most of the state consists of a low plateau with an average elevation of 250-400 m and very little relief. This plateau descends sharply to the coastal plains in many places as a steep escarpment. 


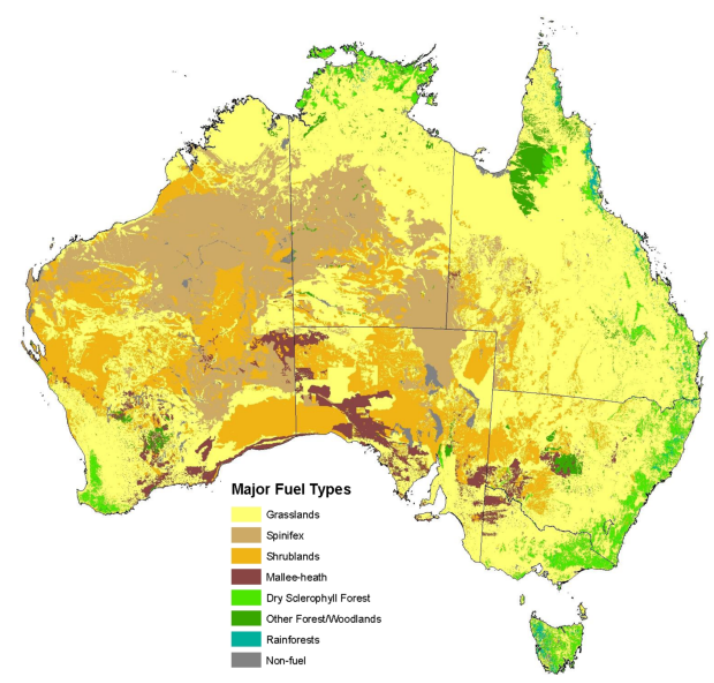

(a)

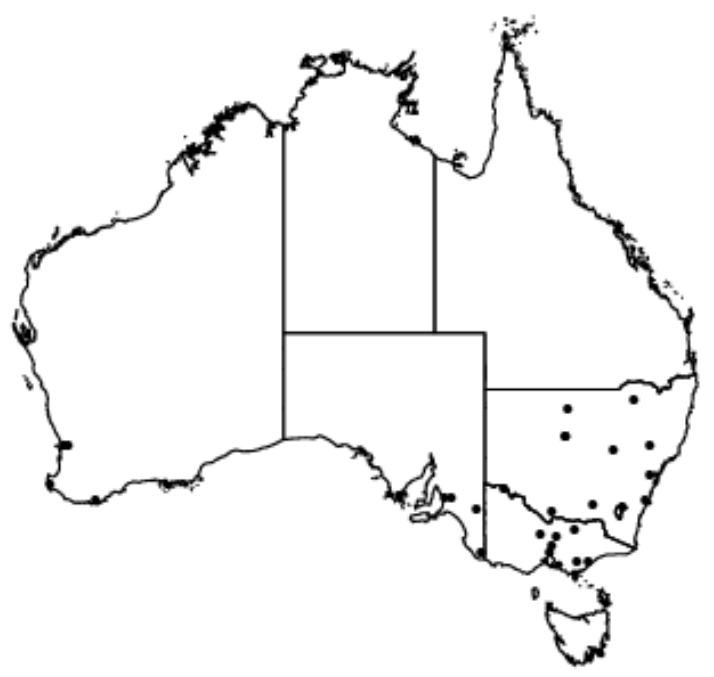

(b)

Figure 1: (a) Map of Australia showing the predominant vegetation classified by bushfire fuel type. Source: Sullivan et al. (2012). (b) Locations of the 28 AWS sites.

The effect of slope is understood to increase the rate of spread of fires with every $10^{\circ}$ of slope doubling the speed of a fire compared to flat ground (McArthur, 1967). The greater variation in topography in the east compared to the west should mean a greater range of slope values and extent that may make a significant difference to the general behaviour of fires, however the fine scale variations may result in little actual difference in potential behaviour.

There are six major climate classifications identified for the continent. The north is dominated by the Tropical classification. Desert dominates the interior. In the south-east and south-west the temperate and grassland zones are where the bulk of the population and significant cropping lands are located. As one would expect, annual rainfall for both temperate regions is very similar, with mean annual rainfall in the region of 800-1200 mm/year.

Despite being in the same climatic zone, however, the south-west of WA differs from the south-east of the continent in that it has a Mediterranean climate in which the summers are hot and dry and the winters wet and cool. In the south-east of the continent, rainfall is more evenly distributed. During the fire season for southern Australia (October to April), the average rainfall for the south-west corner is $200-300 \mathrm{~mm}$, evaporation exceeds rainfall, and it is generally very dry. Over the same period, the average rainfall for the south-east is much greater with values ranging up to $400-600 \mathrm{~mm}$.

The average daily maximum temperatures for the two sides of the continent for the bushfire season period (October-April) are very similar. Despite parts of southern Victoria and eastern NSW having maximum temperatures 3-6 degrees lower than south-west of WA, this is primarily due to difference in topographic elevation over the longer term; these locations can still experience high temperatures over shorter periods.

\subsection{Fire weather climatology}

Foley (1947) undertook a comprehensive assessment of the meteorological aspects associated with fire during the period 1914-1944 at a national level and observed [p.13] that "the most dangerous fires have occurred in Gippsland, the Western Districts and north-eastern districts of Victoria and eastern parts of New South Wales...In the south-west of Western Australia ... summer is normally a dry season in this region and the danger of fire is more persistent than in the south-eastern States." McArthur's work of the 1950s and 1960s developing the Australia fire danger rating systems (McArthur, 1967) was the first comprehensive quantitative approach intended to be applied nationally at a regional scale.

Fire danger is defined as the potential for a fire to break out, spread and do damage (Chandler et al., 1983). In Australia the factors that are used to determine fire danger are fuel type, antecedent weather conditions (rainfall and soil dryness primarily but also fuel condition in grasslands), air temperature, relative humidity and wind speed (i.e., the fire weather variables). For the most part it is the weather factors, collectively known as the fire weather, that drives the variation of fire danger. 
Synoptic situations. The fire weather variables which dominate fire danger vary on a diurnal timescale that is determined by the synoptic mean sea level pressure condition of the weather.

In general there are a large number of common synoptic patterns associated with recurring weather. For example, Treloar and Stern (1993) identified 50 synoptic types for Victoria of which only four were significantly associated with extreme fire weather at Melbourne Airport (Long, 2006). Sullivan et al. (2012) identified four primary synoptic situations associated with the occurrence of severe fire weather for the country. In each case, the synoptic situation is such that pressure systems would direct hot, dry winds from the centre of the continent to the coast. As a result, the overriding weather patterns associated with bad fire weather for each region of the country is different. In the south-east of the country, it is a high pressure system located in the Tasman Sea and an approaching cold front or trough from the south-west. In the south-west, important synoptic features that determine fire weather include the subtropical high pressure system, mid-latitude fronts and the occasional incursion of ex-tropical cyclones south of latitude $30^{\circ} \mathrm{S}$ (McCaw and Hanstrum, 2003; McCaw et al., 2007).

The synoptic situation sets up the potential for a bad fire day. The potential for a fire event is then initiated by antecedent conditions that leave much of the landscape dry and predisposed to burn (i.e., an extended period of rainfall deficit) and an ignition source. Fire events that become disastrous are generally associated with major shifts in wind direction such as those generated by the passage of troughs and frontal systems. Very often, these major wind shifts occur after a fire has started and spread for some hours under the prevailing synoptic situation, resulting in long flanks that suddenly become large headfires in the wake of the wind change.

In eastern Australia, many significant fire events are associated with the passage of large cold fronts out of Bass Strait (Speer et al., 1996). Often the approach of the cold front acts to compress the isobars of the high pressure system, resulting in very strong and gusty winds prior to the arrival of the front. In WA, major shifts in wind direction are associated with the passage of warm west coast troughs (McCaw and Hanstrum, 2003; McCaw et al., 2007). Several distinctive weather patterns responsible for extreme fire weather days in south-western Australia were identified by Bannister and Hanstrum (1995). In south coastal areas, extreme fire weather conditions are linked to the formation of a prefrontal trough and are more frequent in early summer. On the west coast, extreme fire weather typically results from the combination of a strong high to the south of the State and a trough over northern parts of the South West Land Division, a synoptic situation that is most common in January and February.

Sub-synoptic fire weather elements. Within a synoptic pattern associated with extreme fire weather there are sub-synoptic elements that also influence the potential for disastrous fires. Mills (2005a) utilised archived national objective analyses and reanalysis datasets from a 40-year period along with a contemporary operational mesoscale numerical weather prediction model, to investigate the predictability and dynamics of the wind structures over Victoria on Ash Wednesday, 1983 (a day that resulted in extensive high intensity wildfires throughout south-east Australia and the deaths of 76 people) and determine just how meteorologically unusual the event was.

Results of the analysis showed that the strong post-frontal winds that resulted in considerable post-front fire spread and significant impacts were associated with an unusually deep tropospheric trough system, and that particular system was in the strongest $0.1 \%$ as measured by the intensity of the $850 \mathrm{hPa}$ temperature gradient over Victoria. Many of the other major south-eastern fire events within the 40-year period, such as Hobart 1967 and the Western District fires of February 12, 1977, also exhibited the same steep thermal gradient above $850 \mathrm{hPa}$, suggesting that this artefact is a possible indicator of extreme fire weather potential, at least for the south-east of Australia.

Atmospheric stability. Mills (2005b) notes that less predictable fire behaviour has been noted in conditions of decreased atmospheric stability. Atmospheric instability enables greater spread and intensity of bushfires by allowing greater development of the height and strength of the convective plume (Byram, 1954), which in turn promotes lofting and transport of firebrands downwind of the fire, as well as by inducing the mixing down of very dry, gusty upper winds to ground level (Sullivan et al., 2012).

EI Niño-Southern Oscillation (ENSO). Much of the variation in Australian rainfall has been correlated to the ENSO phenomenon, particularly for eastern Australia (Pittock, 1975). There is also statistical evidence that fire danger and the area burnt by wildfires in Victoria, NSW and Tasmania increases during an ENSO event (Skidmore, 1987). The Southern Oscillation Index (SOI) is the difference in mean sea level pressure between Papeete in the South Pacific and Darwin, normalised for each calendar month to a standard deviation equal to 10 (Troup, 1965). Since 1901, there have been 21 years categorised as El Niño years. Pittock (1975) found that there is a correlation between SOI and annual mean rainfall for eastern and northern Australia but 
that the correlation quickly degrades for central, southern and western Australia. Pittock (1984), however, found that the correlations do not remain constant with time, suggesting that there are other factors involved. The links between rainfall and ENSO, while statistically significant for most of the country, is not sufficiently strong to predict rainfall (Nicholls, 1985). Many years of low SOI but which are not considered El Niño years result in drought and other years considered to be El Niño result in average to above average rainfall.

\section{Measure of Fire Danger Conditions and Fire Seasons}

\subsection{Extended fire season and Automatic Weather Station (AWS) sites}

Fire seasons occur at different parts of the year in different parts of the country, however for our purposes we focus on southerly locations, in particular the states of Tasmania, Victoria, NSW, SA and the South West Interconnected System (SWIS) in WA. For the majority of our study region, the fire season occurs in the Summer months, however for areas further south such as Tasmania the season can extend into Autumn, and for northern parts of NSW the season can begin in Spring. For this study we have therefore adopted an extended fire season for all regions that runs from 1 September to 30 April.

We present and analyse a statistical summary of the McArthur Mk 5 Forest Fire Danger Index (FFDI) (McArthur, 1967) data computed for 28 AWS sites selected across the states of interest (Table 1).

\subsection{A new metric of fire danger}

One method to compare sites is to determine a measure of fire risk and then rank sites by this measure. There are a number of individual measures such as number of Extreme FFDI (FFDI $>50$ ) days per season, 90th percentile and maximum FFDI, but each has drawbacks. For example, the maximum FFDI is likely influenced by outliers.

We propose a new metric $(M)$ based on the combination of number of Extreme FFDI days and 90th percentile, both normalised by the maximum value in comparison. Mathematically,

$$
M=N_{e x t, i} / \max \left(N_{e x t}\right)+F_{90, i} / \max \left(F_{90}\right)
$$

where $N_{\text {ext }, i}$ is the number of extreme days per season for site $i, \max \left(N_{\text {ext }}\right)$ is the maximum number of extreme days per season across all sites, $F_{90, i}$ is the 90th percentile FFDI value for site $i$ and $\max \left(F_{90}\right)$ is the maximum such value over the sites. The largest possible value for $M$ is 2 , where the maximum number of extreme days per season and the maximum 90th percentile FFDI value occurred at the same site. In our study, the Bourke airport site in NSW has achieved $M=2$ (see Table 1). This metric emphasises extreme fire weather and is not unduly influenced by outliers.

\subsection{Results}

In Table 1, the sites are ranked by the value of $M$ in ascending order. For this measure, we see that all WA sites with the exception of Perth Airport exhibit a milder fire danger than many others on the east coast. While there are sites with higher FFDI such as Mildura and Bourke that actually have relatively low fire risk in reality due to a scarcity of vegetation, there are several sites in areas of significant available fuel and which are ranked as more dangerous than the WA sites in terms of fire weather. From this, we can suggest that with the exception of the area best represented by Perth Airport (including Perth Hills), the worst fire weather in WA tends not to be as bad as the worst in eastern Australia.

It can be noted that Wallan (Kilmore Gap) in Victoria has only one extreme fire danger day per year on average, and a 90th percentile FFDI that is equal 5th lowest amongst the sites - yet is very close to the ignition point of the Kilmore East fire on Black Saturday 2009, which resulted in the greatest loss of life on that day (Cruz et al., 2012). The danger on that day is reflected somewhat in the maximum FFDI entry for Wallan.

\section{Discussion ANd Conclusions}

Australia is a large continent with a broad spectrum of landscapes and climates. The review of the literature has shown that as the south-west of WA and the south-east of Australia cover similar latitudes there are a number of similarities (annual temperature and rainfall; fuels; fire weather climatology) but also some significant differences (pattern of rainfall; topography; dominant synoptic patterns). As a result there is some evidence of differences in prevailing fire weather existing between WA and eastern Australia 


\begin{tabular}{|c|c|c|c|c|c|c|c|c|c|c|}
\hline Site & State & $\begin{array}{l}\text { No. } \\
\text { days }\end{array}$ & $\begin{array}{l}\text { No. } \\
\text { sea- } \\
\text { sons }\end{array}$ & $\begin{array}{c}\text { No. } \\
\text { VH } \\
\text { days } \\
\text { / season }\end{array}$ & $\begin{array}{l}\text { No. E } \\
\text { days } \\
\text { /season }\end{array}$ & $\begin{array}{l}\text { Mean } \\
\text { FFDI }\end{array}$ & $\begin{array}{c}75 \% \\
\text { quant. } \\
\text { FFDI }\end{array}$ & $\begin{array}{c}90 \% \\
\text { quant. } \\
\text { FFDI }\end{array}$ & $\begin{array}{c}\text { Max } \\
\text { FFDI }\end{array}$ & $M$ \\
\hline WITCHCLIFFE & WA & 3364 & 14 & 5.4 & 0 & 6.9 & 9.4 & 13.8 & 49.9 & 0.297 \\
\hline ALBANY AIRPORT & WA & 4689 & 19.5 & 6.6 & 1.3 & 6.3 & 7.7 & 12.2 & 80.5 & 0.341 \\
\hline NOWRA RAN AIR STATION & NSW & 5537 & 23.1 & 9.7 & 1.1 & 6.3 & 7.4 & 14 & 87.6 & 0.367 \\
\hline EAST SALE AIRPORT & VIC & 4737 & 19.7 & 9.8 & 0.8 & 7.9 & 9.5 & 15.9 & 96.1 & 0.390 \\
\hline WALLAN (KILMORE GAP) & VIC & 4500 & 18.8 & 10.7 & 1 & 6.5 & 8.3 & 15.9 & 142.9 & 0.402 \\
\hline MORWELL (LATROBE VALLEY) & VIC & 3841 & 16 & 10.7 & 1.1 & 7.7 & 10 & 16.5 & 99.1 & 0.421 \\
\hline MOUNT CRAWFORD & SA & 4531 & 18.9 & 20.3 & 1.1 & 8.1 & 11.6 & 22.1 & 70.6 & 0.542 \\
\hline LAMEROO (AUSTIN PLAINS) & SA & 2145 & 8.9 & 20.6 & 2.6 & 7.3 & 2.8 & 21.5 & 84.1 & 0.619 \\
\hline CANBERRA AIRPORT & ACT & 5537 & 23.1 & 25.4 & 1.6 & 11.2 & 15 & 24.6 & 93.2 & 0.625 \\
\hline RICHMOND RAAF & NSW & 5537 & 23.1 & 20.5 & 2.5 & 9.8 & 12.9 & 22.1 & 144.4 & 0.626 \\
\hline BICKLEY & WA & 3796 & 15.8 & 29.4 & 1.3 & 11.8 & 17.5 & 25.5 & 65.3 & 0.627 \\
\hline MOUNT GAMBIER AERO & SA & 5076 & 21.1 & 20.1 & 3.4 & 9.7 & 11.4 & 21.7 & 101 & 0.671 \\
\hline SCONE AIRPORT & NSW & 5537 & 23.1 & 26.6 & 2.4 & 11.2 & 15.2 & 25 & 114.8 & 0.682 \\
\hline PORT LINCOLN & SA & 5076 & 21.1 & 16.5 & 5.6 & 9.8 & 10.2 & 17.3 & 170.3 & 0.709 \\
\hline MANGALORE AIRPORT & VIC & 4737 & 19.7 & 32.7 & 3.2 & 12.9 & 18 & 27.2 & 130.6 & 0.778 \\
\hline BENDIGO AIRPORT & VIC & 4737 & 19.7 & 35.4 & 3.1 & 13.4 & 18.6 & 28.2 & 110.8 & 0.793 \\
\hline MELBOURNE AIRPORT & VIC & 5537 & 23.1 & 28.1 & 5.4 & 11.9 & 14 & 26.1 & 180.7 & 0.887 \\
\hline PERTH AIRPORT & WA & 5537 & 23.1 & 49.7 & 4.5 & 15.3 & 21.4 & 33.4 & 87.7 & 0.989 \\
\hline MOREE AERO & NSW & 5537 & 23.1 & 52.9 & 5.2 & 16.8 & 22.7 & 32.3 & 99 & 1.008 \\
\hline DUBBO AIRPORT & NSW & 5537 & 23.1 & 48.4 & 5.5 & 15.1 & 21.3 & 32 & 98.2 & 1.019 \\
\hline WANGARATTA AERO & VIC & 4266 & 17.8 & 49.4 & 6.4 & 14.8 & 21.5 & 33 & 111.3 & 1.095 \\
\hline WAGGA WAGGA & NSW & 5537 & 23.1 & 51.8 & 7.8 & 15.8 & 22 & 33.8 & 135.3 & 1.197 \\
\hline COBAR MO & NSW & 5537 & 23.1 & 81.8 & 6.8 & 20.6 & 28.3 & 38.5 & 112.8 & 1.238 \\
\hline EDINBURGH RAAF & SA & 5081 & 21.2 & 50.4 & 10.9 & 16.3 & 21.4 & 36.9 & 132 & 1.450 \\
\hline MILDURA AIRPORT & VIC & 5537 & 23.1 & 90 & 11.2 & 21.7 & 29 & 40.7 & 127.7 & 1.550 \\
\hline COBAR AIRPORT & NSW & 4810 & 20 & 93.8 & 11.9 & 22 & 30.5 & 42.4 & 107.4 & 1.629 \\
\hline DENILIQUIN AIRPORT & NSW & 3841 & 16 & 79.4 & 12.8 & 20.4 & 28.4 & 41.5 & 118 & 1.664 \\
\hline BOURKE AIRPORT & NSW & 3441 & 14.3 & 116.6 & 16.6 & 25.2 & 35.3 & 46.5 & 96.2 & 2.000 \\
\hline
\end{tabular}

Table 1: 28 sites ranked by $M$. FFDI = McArthur Forest Fire Danger Index; VH = Very High $(24 \leq$ FFDI $<$ $50)$; $\mathrm{E}=$ Extreme $($ FFDI $\geq 50)$; Fire season = 1 September to 30 April; Bureau of Meteorology data period = 1 September 1990 to 26 March 2013;

Historical occurrence of disastrous fires in the last 50 years shows a bias with a greater number of such fires occurring in the south-east of the continent. While disastrous fires have occurred in the west, particularly in the first half of the previous century (Foley, 1947), the scale of the recent fire history differences between the two sides of the continent in our view suggests that this reduction in potential is due to other factors. Changes to the way fuels and fires are managed in WA as a result of these events (in particular the Dwellingup fire of 1961) may have acted to reduce the frequency of such fires. The potential for such fires to occur, however, still remains.

From a statistical perspective, the analysis of the historical weather conditions over the past 23 years from selected sites across the southern half of Australia suggests that there are differences in the occurrence and intensity of weather-driven fire danger conditions in the south-west of WA compared to the south-east of the continent. Areas of WA that are represented by Bickley, Albany and Witchcliffe AWS sites exhibit a milder fire danger than other representative sites on the east coast. We suggest that with the exception of the area best represented by Perth Airport (including Perth Hills), the worst fire weather in WA tends not to be as bad as the worst in eastern Australia. A larger sample of sites would be needed in order for a more confident conclusion to be drawn, which is a part of future work. However, disastrous fire is a chance event that can occur in regions that do not have the most threatening fire weather history.

\section{REFERENCES}

Bannister, A. J. and Hanstrum, B. N. (1995). A climatology of extreme fire weather days in southern Western Australia. Technical report, Bureau of Meteorology, Perth.

Byram, G. M. (1954). Atmospheric conditions related to blowup fires. Station Paper No. 35, USDA Forest Service, Southeastern Forest Experiment Station, Asheville NC.

Chandler, C., Cheney, P., Thomas, P., Trabaud, L., and Williams, D. (1983). Fire in Forestry 1: Forest Fire Behaviour and Effects. John Wiley \& Sons, New York. 
X.G. Lin et al., Initial Analysis of Fire Weather Characteristics

Cheney, N. P., Gould, J. S., and Catchpole, W. R. (1993). The influence of fuel, weather and fire shape variables on fire-spread in grasslands. International Journal of Wildland Fire, 3(1):31-44.

Countryman, C. M. (1966). The concept of the fire environment. Fire Control Notes, 27:8-10.

Cruz, M. G., Sullivan, A. L., Gould, J. S., Sims, N. C., Bannister, A. J., Hollis, J. J., and Hurley, R. (2012). Anatomy of a catastrophic wildfire: the Black Saturday Kilmore East fire in Victoria, Australia. Forest Ecology and Management, 284:269-285.

Foley, J. C. (1947). A study of meteorological conditions associated with bush and grass fires and fire protection strategy in Australia. Bulletin No. 38, Bureau of Meteorology.

Fox-Hughes, P. (2008). A fire danger climatology for tasmania. Australian Meteorological Magazine, 57(2):109-120.

Long, M. (2006). A climatology of extreme fire weather days in Victoria. Australian Meteorological Magazine, 55(1):3-18.

Luke, R. H. and McArthur, A. G. (1978). Bushfires in Australia. Australian Government Publishing Service, Canberra.

McArthur, A. G. (1967). Fire behaviour in eucalypt forests. Forestry and Timber Bureau Leaflet 107, Commonwealth Department of National Development, Canberra.

McCaw, L. and Hanstrum, B. (2003). Fire environment of Mediterranean south-west Western Australia.Perth, Australia, 16-18 April 2002. In Abbott, I. and Burrows, N., editors, Fire in ecosystems of south-west Western Australia: impacts and management. Symposium proceedings (Volume I), pages 87-106. Backhuys Publishers.

McCaw, L., Marchetti, P., Elliott, G., and Reader, G. (2007). Bushfire weather climatology of the Haines Index in southwestern Australia. Australian Meteorological Magazine, 56(2):75-80.

Mills, G. A. (2005a). A re-examination of the synoptic and mesoscale meteorology of Ash Wednesday 1983. Australian Meteorological Magazine, 54(1):35-55.

Mills, G. A. (2005b). On the subsynoptic-scale meteorology of two extreme fire weather days during the Eastern Australian fires of January 2003. Australian Meteorological Magazine, 54(4):265-290.

Nicholls, N. (1985). Towards the prediction of major Australian droughts. Australian Meteorological Magazine, 33:161-166.

Pittock, A. B. (1975). Climatic change and the patterns of variation in Australian rainfall. Search, 6:498-504.

Pittock, A. B. (1984). On the reality, stability and usefulness of southern hemisphere teleconnections. Australian Meteorological Magazine, 32:75-82.

Skidmore, A. (1987). Predicting bushfire activity in Australia from El Nino/Southern Oscillation events. Australian Forestry, 50:231-235.

Speer, M. S., Leslie, L. M., Colquhoun, J. R., and Mitchell, E. (1996). The Sydney Australia wildfires of January 1994 - Meteorological conditions and high resolution numerical modeling experiments. International Journal of Wildland Fire, 6(3):145-154.

Sullivan, A. L., McCaw, W. L., Cruz, M. G., Matthews, S., and Ellis, P. F. (2012). Fuel, fire weather and fire behaviour in Australian ecosystems. In Bradstock, R. A., Gill, A. M., and Williams, R. D., editors, Flammable Australia: Fire Regimes, Biodiversity and Ecosystems in a Changing World, chapter 3, pages 51-77. CSIRO Publishing, Collingwood, Vic, 2nd edition.

Treloar, A. B. A. and Stern, H. (1993). A climatology and classification of Victorian severe thunderstorms. In 4th Int. Conf. On Southern Hemisphere Meteorology and Oceanography, Hobart, page 533. Co-sponsored by Australian Academy of Sciences, Intergovernmental Oceanographic Commission and the World Meteorological Organisation, American Meteorological Society.

Troup, A. J. (1965). The 'southern oscillation'. Quarterly Journal of the Royal Meteorological Society, 91 (390):490-506. 